\title{
Association between maternal serum beta human chorionic gonadotropin levels and hypertensive disorders of pregnancy
}

\author{
Archana Kumari, Vahini M.*
}

Department of Obstetrics and Gynecology, Rajendra Institute of Medical Sciences, Ranchi, Jharkhand, India

Received: 22 June 2020

Accepted: 29 June 2020

\section{*Correspondence:}

Dr. Vahini M.,

E-mail: vahini.m91@gmail.com

Copyright: () the author(s), publisher and licensee Medip Academy. This is an open-access article distributed under the terms of the Creative Commons Attribution Non-Commercial License, which permits unrestricted non-commercial use, distribution, and reproduction in any medium, provided the original work is properly cited.

\begin{abstract}
Background: A major challenge in obstetrics is early identification of hypertensive disorders of pregnancy (HDP). This study was performed to determine the association between elevated maternal serum $\beta$-hCG levels and HDP, the correlation between serum $\beta$-hCG level and severity of preeclampsia and to determine the value of serum $\beta$-hCG level as a diagnostic marker for early diagnosis of HDP.

Methods: This was a hospital based observational study conducted in the department of obstetrics and gynecology, Rajendra Institute of Medical Sciences, Ranchi on 375 pregnant women with period of gestation more than 20 weeks, including 250 pregnant women with HDP as study group and 125 normotensive pregnant women as controls. Serum $\beta$-hCG concentration was measured and its level was compared between two groups.

Results: The maternal mean serum $\beta$-hCG levels $(51161.08 \pm 30038.21 \mathrm{IU} / \mathrm{L})$ of study group of HDP were higher than the normotensive control group $(17603.23 \pm 16748.21 \mathrm{IU} / \mathrm{L})$. In non-severe preeclampsia, the mean serum levels were $36417.32 \pm 23876.74 \mathrm{IU} / \mathrm{L}$ while in severe preeclampsia, 60030.34 $\pm 28771.31 \mathrm{IU} / \mathrm{L}$. There was statistically significant difference $(\mathrm{p}<0.001)$ with higher levels in early onset preeclamptic mothers than late onset preeclampsia. The cut-off point of $\beta$-hCG for predicting HDP was 32077 IU/L with sensitivity of $65 \%$ and specificity of $86 \%$.

Conclusions: Serum $\beta$-hCG level is higher in HDP when compared to normotensive women. Higher levels of $\beta$-hCG are associated with increasing severity of hypertensive disorders of pregnancy. The utility of serum $\beta$-hCG as a diagnostic test is limited because of low sensitivity and difficulty in deciding the cut-off value.
\end{abstract}

Keywords: Eclampsia, Hypertensive disorders of pregnancy, Preeclampsia, Serum $\beta$-hCG

\section{INTRODUCTION}

Hypertensive disorders of pregnancy (HDP) remain one of the most intriguing unsolved problems in obstetrics. How pregnancy incites or aggravates hypertension remains unsolved despite decades of intensive research. Although improvements in obstetrical and neonatal care have led to a reduction in morbidity and mortality from hypertensive disorders, our ability to predict the condition has not improved significantly. The prevalence of hypertensive disorders of pregnancy was $7.8 \%$, with preeclampsia in $5.4 \%$ of the study population in India. ${ }^{1}$ Approximately 1 in 2000 deliveries is complicated by eclampsia in developed countries whereas the incidence in developing countries is estimated around 1 in 100 to 1 in 1700 cases. $^{2,3}$

Preeclampsia was once called "the disease of theories", but research efforts in the past decade have produced exciting breakthroughs. One of the hypothesized etiologies of HDP is placental vascular remodelling with incomplete trophoblastic invasion. Various studies have shown that placental hypoxia might be responsible for increased hCG production. It was proved by in vitro trophoblastic cell culture that was grown under hypoxic conditions. Placental abnormalities like villitis, infarction, ischemic changes and intervillous thrombosis were also associated with increased serum $\beta$-hCG levels. ${ }^{4}$ The 
impaired spiral artery vasculature and subsequent reduced blood flow in the placental villi were responsible for intrauterine growth restriction seen in severe forms of hypertensive disorders of pregnancy.

As it is postulated that preeclampsia is a trophoblastic disorder and hCG is secreted from the trophoblasts, it has become essential to understand this disease, to investigate the pathologic and secretory reaction of the placenta. ${ }^{5}$ Twin pregnancies and molar pregnancies produce higher levels of hCG and they are associated with higher incidence of preeclampsia than uncomplicated singleton pregnancies. ${ }^{6,7}$ Since preeclampsia is a prevalent problem in our society and the largest contributor of maternal mortality nearly to the extent of $28.8 \%$ in Jharkhand and with its pathogenesis not clearly explained, this study was performed to determine the association between maternal serum $\beta$-hCG levels and hypertensive disorders of pregnancy for its prediction. ${ }^{8}$

\section{METHODS}

This was a hospital based observational study conducted in the department of obstetrics and gynecology, Rajendra Institute of Medical Sciences, Ranchi from $1^{\text {st }}$ August, 2017 to $31^{\text {st }}$ October, 2018 over a period of 15 months after taking approval from the ethical committee. This study included 375 pregnant women, grouped into cases of 250 pregnant women with hypertensive disorders of pregnancy and control of 125 normotensive women. Serum $\beta$-hCG levels were measured and compared in both groups.

\section{Inclusion criteria}

Study group: This included 250 pregnant women with gestational age more than 20 weeks, fulfilling the criteria as any of the following three subgroups;

- Gestational hypertension: Pregnant women with gestational age more than 20 weeks with blood pressure, systolic $\geq 140 \mathrm{mmHg}$ and diastolic $\geq 90$ $\mathrm{mmHg}$ with no proteinuria.

- Preeclampsia (non-severe and severe): Pregnant women with gestational hypertension with proteinuria and imminent symptoms like headache, epigastric pain, thrombocytopenia, altered renal function test, elevated liver enzymes, pulmonary edema.

- Eclampsia: Preeclamptic women with convulsions.

Control group: This included 125 pregnant women with gestational age more than 20 weeks, who were normotensive with blood pressure, systolic $<140 \mathrm{mmHg}$ and diastolic $<90 \mathrm{mmHg}$.

\section{Exclusion criteria}

Pregnant women more than 20 weeks of gestation with
- Multiple pregnancy

- Gestational diabetes mellitus

- Medical disease like chronic hypertension, chronic renal disease, chronic liver disease, cardiac disease, SLE or hematological disorders.

A thorough evaluation was done including a detailed history, physical examination (general and systemic) to confirm the above-mentioned inclusion and exclusion criteria. A written informed consent was taken after explaining the procedure about measurement of blood pressure, taking of urine samples for proteinuria, collection of blood sample for serum $\beta$-hCG.

\section{Measurement of blood pressure}

Mercury sphygmomanometer was used to measure the blood pressure. An appropriate size cuff (length 1.5 times the upper arm circumference or a cuff with a bladder that encircles $80 \%$ or more of the arm) was used, with the patients in an upright position with their right arm supported in horizontal position at the level of the heart, after a 10 minute or longer rest period, and also when the patient is in left lateral recumbent position with the arm at the level of the heart. Diastolic blood pressure was determined by disappearance of sound (Korotkoff phase V) rather than by muffling of sound (Korotkoff phase IV) as it is more reproducible and shows better correlation with true diastolic blood pressure in pregnancy. Where $\mathrm{KV}$ is absent, KIV was accepted.

\section{Assessment of proteinuria}

Visual dipstick test was used to measure proteinuria.

\section{Blood sample collection}

Venous blood samples (about $3 \mathrm{ml}$ ) were collected in test tube with aseptic precautions. After 2 hours of collection, sample was centrifuged at $3000 \mathrm{rpm}$ for 5 minutes. Serum was separated and collected in polythene tube with cork. The sera with no sign of hemolysis were used for the analysis of $\beta$-hCG.

\section{Biochemical analysis}

Serum $\beta$-hCG concentration was measured by solidphase, two site chemiluminescence immunoassay (CLIA). Authors used fully automated enzyme amplified chemiluminescent immunoassay based Immulite 1000 analyser.

\section{Statistical analysis}

Proper template for data entry was generated on MS Excel and data was entered on this template. The data was compiled and subjected to analysis using statistical package for social sciences (SPSS) and interpreted according to the type of variables. The continuous variables were analyzed in terms of mean and interpreted 
by Student's t-test. The discontinuous variables were described in terms of percentages and interpreted by $\chi^{2}$ (Chi-square) test. Data pertaining to $\beta$-hCG levels were analyzed using non-parametric tests - Mann Whitney U and Kruskal Wallis tests as the data was skewed and did not follow normal distribution. 5\% level of significance $(\mathrm{p}<0.05)$ was considered for the study.

\section{RESULTS}

Out of the 250 hypertensive women in the study group, there were $42(20 \%)$ patients with gestational hypertension, 50 (20\%) with non-severe preeclampsia, 99 $(39.6 \%)$ with severe preeclampsia and 59 (23.6\%) with antepartum eclampsia. The mean age of normotensive mothers in control group was 23.78 years and that of hypertensive mothers in the study group was 23.82 years and were statistically similar.

Table 1 shows that the difference in parity of mothers was statistically significant $(\mathrm{p}<0.05)$ with a greater number of primigravida in the study (hypertensive) group as compared to control (normotensive) women.

Figure 1 shows the distribution of cases according to gestational age. Most of the patients $(54.7 \%)$ in the study belonged to the gestational age between 37 weeks and 40 weeks 6 days. The difference in gestational age between the two groups was statistically significant $(\mathrm{p}<0.05)$. Mean gestational age was $37.9 \pm 2.7$ weeks in the normotensive group and $35.9 \pm 3.3$ weeks in the hypertensive group.

Table 1: Comparison between study group (hypertensive) and control (normotensive) mothers group in respect to parity.

\begin{tabular}{|c|c|c|c|c|c|c|c|c|c|}
\hline \multirow{2}{*}{ Gravida } & \multicolumn{2}{|c|}{ Normotensives $(\mathrm{n}=\mathbf{1 2 5})$} & \multicolumn{2}{|c|}{ Hypertensives $(\mathrm{n}=250)$} & \multicolumn{2}{|c|}{ Total $(n=375)$} & \multirow[t]{2}{*}{ Chi Sq. } & \multirow[t]{2}{*}{ Df } & \multirow[t]{2}{*}{ Significance } \\
\hline & No & $\%$ & No & $\%$ & No & $\%$ & & & \\
\hline Primi & 54 & $43.2 \%$ & 138 & $55.2 \%$ & 192 & $51.2 \%$ & \multirow{3}{*}{4.8028} & \multirow{3}{*}{1} & \multirow{3}{*}{$\mathrm{p}=0.028414$} \\
\hline Multi & 71 & $56.8 \%$ & 112 & $44.8 \%$ & 183 & $48.8 \%$ & & & \\
\hline Total & 125 & & 250 & & 375 & $100.0 \%$ & & & \\
\hline
\end{tabular}

Table 2: Comparison of systolic (SBP) and diastolic blood pressure (DBP) between study (hypertensive) and control (normotensive mothers groups).

\begin{tabular}{|c|c|c|c|c|c|c|c|}
\hline \multirow[t]{2}{*}{ Blood pressure } & \multicolumn{2}{|c|}{ Normotensives $(\mathrm{n}=\mathbf{1 2 5})$} & \multicolumn{2}{|c|}{ Hypertensives ( $n=250)$} & \multirow[t]{2}{*}{ "to" } & \multirow[t]{2}{*}{ Df } & \multirow[t]{2}{*}{ Significance } \\
\hline & Mean & SD & Mean & SD & & & \\
\hline $\mathrm{SBP}(\mathrm{mm} \mathrm{Hg})$ & 111.98 & 10.14 & 151.76 & 18.78 & 26.618 & 373 & $\mathrm{p}<0.001$ \\
\hline $\mathrm{DBP}(\mathrm{mm} \mathrm{Hg})$ & 74.8 & 5.62 & 106.88 & 12.82 & 33.627 & 373 & $\mathrm{p}<0.001$ \\
\hline
\end{tabular}

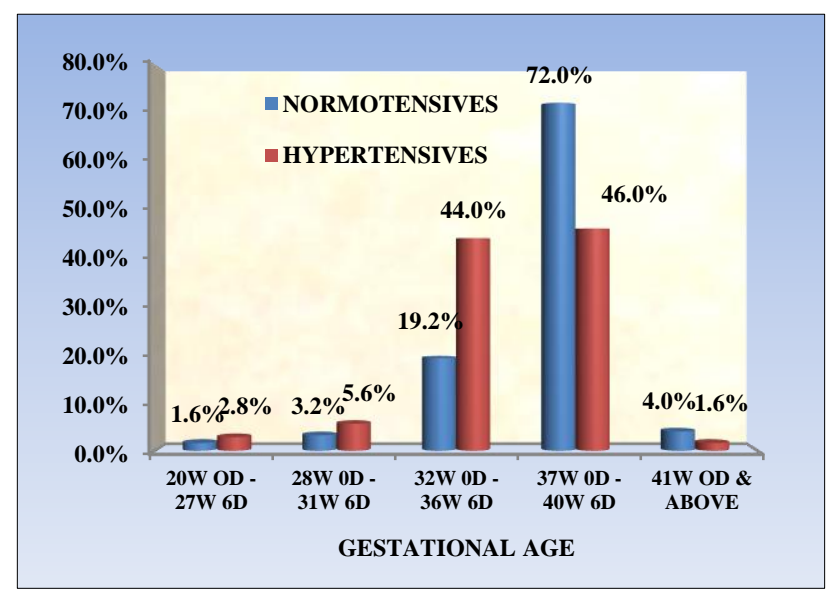

Figure 1: Distribution of cases according to gestational age.

Table 2 shows comparison of systolic blood pressure (SBP) and diastolic blood pressure (DBP) of the women in study and control group. The mean SBP of mothers with HDP was $151.76 \pm 18.78 \mathrm{mmHg}$ and that of normotensive mothers was $111.98 \pm 10.14 \mathrm{mmHg}$ which was statistically significant $(\mathrm{p}<0.001)$. The mean DBP of hypertensive mothers was $106.88 \pm 6.2 \mathrm{mmHg}$ and that of the normal mothers was $74.8 \pm 5.62 \mathrm{mmHg}$ which was also statistically significant $(\mathrm{p}<0.001)$.

From Table 3, it is observed that there was statistically significant difference $(\mathrm{p}<0.001)$ in the presence of proteinuria between the two groups. $82.8 \%$ of hypertensive mothers had proteinuria whereas only $18.4 \%$ of normotensive mothers had proteinuria (visual dipstick of trace).

Figure 2 shows the distribution of proteinuria among the women with hypertensive disorders of pregnancy, $38 \%$ had protein dipstick of $1+$ (equivalent to $0.3 \mathrm{~g} / \mathrm{L}$ ) and $35.6 \%$ had protein dipstick of $2+$ (equivalent to $1.0 \mathrm{~g} / \mathrm{L}$ ).

Table 4 shows that the mean serum $\beta$-hCG level of severe preeclamptic mothers $(60030.34 \pm 28771.31$ IU/L) was higher than non-severe preeclamptic mothers 
Table 3: Comparison of presence of proteinuria between women with HDP and normotensive mothers.

\begin{tabular}{|c|c|c|c|c|c|c|c|c|c|}
\hline \multirow{2}{*}{ Proteinuria } & \multicolumn{2}{|c|}{ Normotensives ( $\mathrm{n}=\mathbf{1 2 5})$} & \multicolumn{2}{|c|}{ Hypertensives ( $\mathrm{n}=\mathbf{2 5 0})$} & \multicolumn{2}{|c|}{ Total $(n=375)$} & $\chi^{2}$ & Df & Significance \\
\hline & No. & $\%$ & No. & $\%$ & No. & $\%$ & \multirow{4}{*}{145.73} & \multirow{4}{*}{1} & \multirow{4}{*}{$\mathrm{P}<0.001$} \\
\hline Absent & 102 & $81.6 \%$ & 43 & $17.2 \%$ & 145 & $38.6 \%$ & & & \\
\hline Present & $23^{*}$ & $18.4 \%$ & 207 & $82.8 \%$ & 230 & $61.3 \%$ & & & \\
\hline Total & 125 & & 250 & & 375 & & & & \\
\hline
\end{tabular}

*Proteinuria with approximate equivalence of 0.15 to $0.3 \mathrm{~g} / \mathrm{L}$.

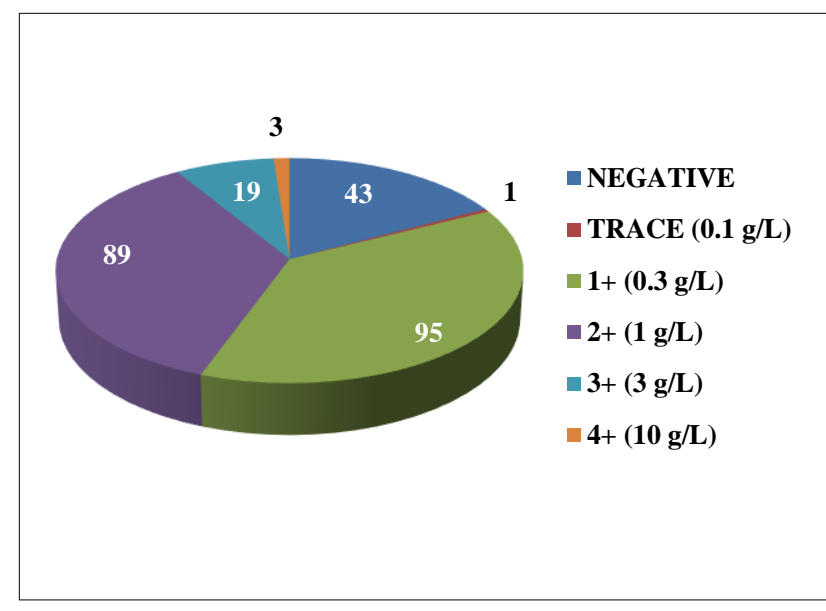

Figure 2: Distribution of proteinuria in women with hypertensive disorders of pregnancy.

Table 5 shows $\beta$-hCG levels of study group and control group with respect to their parity. Among primigravida, the difference in $\beta$-hCG levels between control (normotensives) and study (hypertensives) mothers was statistically significant $(\mathrm{p}<0.001)$. Similarly, among multigravida, the difference was statistically significant $(p<0.001)$ with higher levels of $\beta-h C G$ in hypertensive mothers. When comparing the $\beta$-hCG levels between primi and multigravid in control group (normotensives), there was no significant difference $(p>0.05)$. There was statistically significant difference $(p<0.05)$ between $\beta$ hCG levels of primi and multigravid of the study group (hypertensives) with higher levels in the primigravida patients.

Table 6 shows the comparison of $\beta$-hCG values in two groups in respect to their gestational age, $\leq 34$ weeks and $>34$ weeks. In both the groups, the values were higher in preeclamptic mothers which was statistically significant $(\mathrm{p}<0.001)$. Comparing the $\beta$-hCG values of early and late onset preeclamptic mothers, there was statistically significant difference $(\mathrm{p}<0.001)$ with higher levels in early onset preeclamptic mothers.

Table 4: Comparison of serum $\beta$-hCG between non-severe preeclamptic and severe preeclamptic mothers.

\begin{tabular}{|c|c|c|c|c|c|}
\hline B-hCG (IU/L) & $\begin{array}{l}\text { Non-severe preeclampsia } \\
(\mathrm{n}=50)\end{array}$ & $\begin{array}{l}\text { Severe preeclampsia } \\
(\mathrm{n}=99)\end{array}$ & $\begin{array}{l}\text { Mann Whitney } \\
\text { U test value }\end{array}$ & Df & Significance \\
\hline Mean & 36417.32 & 60030.34 & \multirow{3}{*}{7.7857} & \multirow{3}{*}{147} & \multirow{3}{*}{$\mathrm{p}<0.001$} \\
\hline SD & 23876.74 & 28771.31 & & & \\
\hline Median & 32476.5 & 67089 & & & \\
\hline
\end{tabular}

Table 5: Comparison of serum levels of $\beta$-hCG in primigravida and multigravida women.

\begin{tabular}{|lllll|}
\hline $\begin{array}{l}\text { Serum } \boldsymbol{\beta}- \\
\text { hCG }(\text { IU/L) }\end{array}$ & Primigravida $(\mathbf{n = 1 9 2})$ & Multigravida $(\mathbf{n = 1 8 3})$ & Hypertensives $(\mathbf{n}=\mathbf{1 1 2})$ \\
\hline Mean & 18057.13 & 52875.15 & 17027.08 & 49049.1 \\
\hline SD & 16722.87 & 29661.77 & 16691.06 & 30496 \\
\hline Median & 13959.5 & 55394.6 & 10420 & 45019 \\
\hline Significance & Mann Whitney U test 12.189 Df=190 $\mathrm{p}<0.001$ & Mann Whitney U test $9.8945 \mathrm{Df}=181 \mathrm{p}<0.001$ \\
\hline
\end{tabular}

Table 7 shows the comparison of the serum $\beta$-hCG levels between different categories of hypertensive disorders of pregnancy using Kruskal - Wallis test. The mean $\beta$-hCG levels were observed as follows: for gestational 
hypertension, 20950.28 $\pm 10681.29 \mathrm{IU} / \mathrm{L} ;$ non-severe preeclampsia, $36417.32 \pm 23876.74 \quad \mathrm{IU} / \mathrm{L} ; \quad$ severe preeclampsia, 60030.34 $\pm 28771.31 \mathrm{IU} / \mathrm{L}$ and antepartum eclampsia, 72279.46 $\pm 23628.03 \mathrm{IU} / \mathrm{L}$ and it was seen that there was a significant difference between the different categories of HDP $(\mathrm{p}<0.05)$.

Table 6: Maternal serum levels of $\beta$-hCG in early and late onset pre-eclampsia.

\begin{tabular}{|c|c|c|c|c|}
\hline \multirow[b]{2}{*}{$\begin{array}{l}\text { Serum } \boldsymbol{\beta} \text {-hCG } \\
\text { (IU/L) }\end{array}$} & \multicolumn{2}{|c|}{ Early onset ( $\leq 34$ weeks) $(n=52)$} & \multicolumn{2}{|c|}{ Late onset (>34 weeks) $(\mathrm{n}=222)$} \\
\hline & $\begin{array}{l}\text { Normotensives } \\
(n=11)\end{array}$ & $\begin{array}{l}\text { Preeclampsia } \\
(n=41)\end{array}$ & $\begin{array}{l}\text { Normotensives } \\
(\mathrm{n}=114)\end{array}$ & $\begin{array}{l}\text { Preeclampsia } \\
(n=108)\end{array}$ \\
\hline Mean & 21784.27 & 56293.24 & 17055.97 & 50517.7 \\
\hline SD & 20900.6 & 31855.54 & 16229.27 & 28350.12 \\
\hline Median & 16083 & 56909 & 12016.5 & 34987 \\
\hline Significance & \multicolumn{2}{|c|}{$\begin{array}{l}\text { Mann Whitney U test value }=5.08489 \\
D f=50 p<0.001\end{array}$} & \multicolumn{2}{|c|}{$\begin{array}{l}\text { Mann Whitney U test value }=7.35555 \\
D f=220 p<0.001\end{array}$} \\
\hline
\end{tabular}

Table 7: Comparison of serum $\beta$-hCG levels between different categories of hypertensive disorders of pregnancy.

\begin{tabular}{|lllll|}
\hline $\begin{array}{l}\text { Serum } \\
\boldsymbol{\beta} \text {-hCG (IU/L) }\end{array}$ & $\begin{array}{l}\text { Gestational } \\
\text { hypertension }(\mathbf{n = 4 2})\end{array}$ & $\begin{array}{l}\text { Non-severe } \\
\text { preeclampsia }(\mathbf{n = 5 0})\end{array}$ & $\begin{array}{l}\text { Severe preeclampsia } \\
(\mathbf{n = 9 9})\end{array}$ & $\begin{array}{l}\text { Antepartum } \\
\text { eclampsia }(\mathbf{n = 5 9})\end{array}$ \\
\hline Mean & 20950.28 & 36417.32 & 60030.34 & 70279.46 \\
\hline SD & 10681.29 & 23876.74 & 28771.31 & 23628.03 \\
\hline Median & 19215 & 32476.5 & 67089 & 74129 \\
\hline $\begin{array}{l}\text { Kruskal Wallis test } \\
\text { Significance }\end{array}$ & Median=52597.2, Chi-square 73.171, Df=3, p=0.000 & \\
\hline
\end{tabular}

From the receiver operating characteristic (ROC) curve, it is observed that the cut-off point of $\beta$-hCG for predicting hypertensive disorder of pregnancy was 32077 IU/L with sensitivity of $65 \%$ and specificity of $86 \%$. The area under the curve was $84.6 \%$ and the test is best fit (Figure 3).

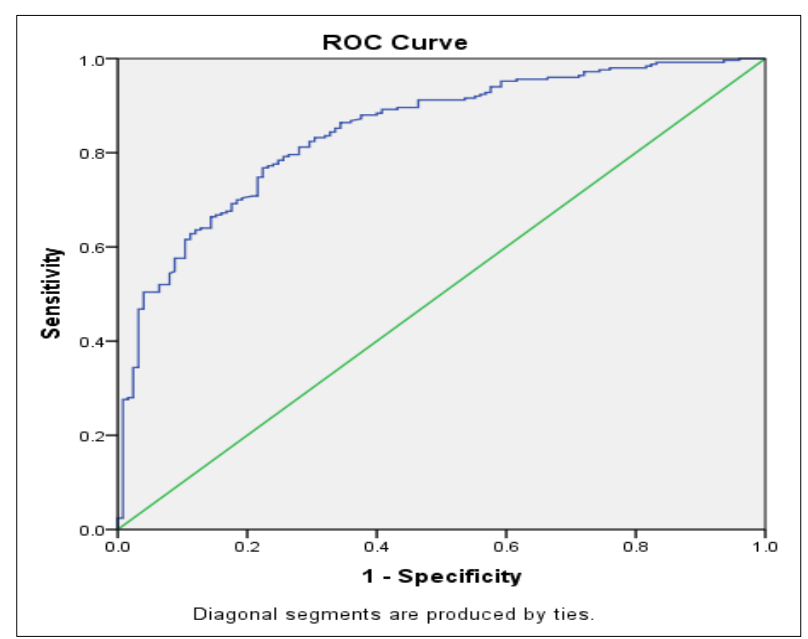

Figure 3: Maternal serum level of $\beta$-hCG as a diagnostic test for hypertensive disorder of pregnancy.

\section{DISCUSSION}

According to WHO reviews, in developed countries $16 \%$ of maternal deaths are reported to be due to hypertensive disorders of pregnancy. This proportion is greater than three other leading causes such as hemorrhage (13\%), abortion ( $8 \%$ ), sepsis $(2 \%)$. Of the $16 \%$ maternal deaths which were attributed to hypertensive disorders, over half of these were preventable. ${ }^{9}$ Approximately 1 in 2000 deliveries is complicated by eclampsia in developed countries whereas the incidence in developing countries is estimated around 1 in 100 to 1 in 1700 cases. $^{3,4}$

This study was a genuine attempt to establish one of the tests by which hypertensive disorders of pregnancy (HDP) can be recognized earlier and its severity envisaged This study was performed to determine the association between elevated maternal serum $\beta$-hCG levels and Hypertensive Disorders of Pregnancy, to compare the serum $\beta$-hCG levels between women with HDP and normotensive pregnant women and also to establish correlation between maternal serum $\beta$-hCG levels and degree of severity of preeclampsia.

Mean age was found to be comparable in two groups 23.78 years in control group and 23.82 years in study group with no statistically significant difference. Studies by Begum $\mathrm{Z}$ et al, Basirat et al, Choudhury et al, also show similar results with no significant correlation of maternal age between the hypertensive and normotensive groups. ${ }^{10-12}$ However, Mujawar et al, observed that maternal age was significantly different between the groups $(\mathrm{p}<0.05)$ with mean age of $26.4 \pm 4.48$ years in the control group and $23.6 \pm 4.16$ years in the preeclampsia group. ${ }^{13}$ 
With respect to parity, there was statistically significant difference $(p<0.05)$ between the two groups with $55.2 \%$ primigravida and $44.8 \%$ multigravida women in the study group and $43.2 \%$ of primi and $56.8 \%$ of multigravida women in the control group. Similar results were seen in the study by Kaur $\mathrm{G}$ et al where the occurrence of PIH was more among primigravida with $17 \%$ developing $\mathrm{PIH}$ and $7.14 \%$ among multigravida but there was no statistically significant association. ${ }^{14}$ In the study by Begum $\mathrm{Z}$ et al there was no significant difference between the 2 groups with respect to parity. ${ }^{10}$

Mean gestational age was $37.9 \pm 2.7$ weeks in the normotensive group and $35.9 \pm 3.3$ weeks in the hypertensive group and this was statistically significant $(\mathrm{p}<0.05)$. In a study by Al-bayati MM et al, it was observed that mean gestational age of normotensive mothers was $37.11 \pm 1.98$ weeks and that of hypertensive mothers was $35.72 \pm 1.93$ weeks and this was statistically significant $(\mathrm{p}<0.001) .{ }^{15}$ But in contrast, Begum $\mathrm{Z}$ et al observed mean gestational age to be $33.3 \pm 3.6$ weeks in the study group and $32.7 \pm 4.2$ weeks in the control group which was not statistically significant. ${ }^{10}$

Statistically significant difference was observed about SBP and DBP between the two groups in the present study, which is similar to findings in several other studies. $^{11-13}$

The mean $\beta$-hCG of hypertensive mothers was $51161.08 \pm 30038.21 \mathrm{IU} / \mathrm{L}$ and that of normotensive mothers was $17603.26 \pm 16748.21 \mathrm{IU} / \mathrm{L}(\mathrm{p}<0.001)$. It was also observed that the mean $\beta$-hCG level of severe preeclamptic mothers $(60030.34 \pm 28771.31$ IU/L) was higher than non-severe preeclamptic mothers (36417.32 \pm 23876.74 IU/L) $\quad(p<0.001)$. Similar results were noted in the studies by Begum $\mathrm{Z}$ et al, Mujawar et al with higher levels of serum $\beta$-hCG levels in the case group of preeclampsia. ${ }^{10,13}$ Other similar studies also observed the correlation between severity of preeclampsia with rise in serum $\beta$-hCG levels. ${ }^{14,16}$

Among primigravida and multigravida in both the groups, there was statistically significant difference $(p<0.001)$ with higher levels of $\beta$-hCG in hypertensive mothers. Among the hypertensive mothers, higher levels were noted in the primigravida patients $(\mathrm{p}<0.05)$. A study by Mooney RA et al demonstrated a decrease in maternal serum hCG with increasing parity. The decrease in hCG was similar at each gestational week from 15-20. In contrast, MSAFP and MSAFP MoM were unaffected by parity. ${ }^{17}$

In this study, early onset preeclamptic women had higher mean serum $\beta$-hCG levels than late onset preeclamptic women. This is in agreement with Shenhav $\mathrm{S}$ et al, they related this finding to the severity of endothelial cell dysfunction in early onset disease. ${ }^{18}$ This is most probably due to altered placental perfusion resulting from incomplete trophoblastic invasion of uterine spiral arteries leading to placental hypoxia and altered secretory function of trophoblastic cells. However, a few other studies reported greater serum $\beta$-hCG levels in late onset preeclamptic women than in early onset preeclamptic women. ${ }^{19,20}$ Huppertz et al suggested that early and late onset preeclampsia had different etiologies and different clinical expressions. In late onset preeclampsia, the behavior of the uterine arteries is normal or only slightly altered but in the early onset disease vascular damages are more prominent. ${ }^{21}$

Nothing significant has been documented in other studies regarding the association of serum $\beta$-hCG levels and different categories of hypertensive disorders of pregnancy, mainly gestational hypertension and antepartum eclampsia.

In the present study, receiver operating characteristic curve identified that with cutoff point of 32077 IU/L, the sensitivity and specificity of $\beta-\mathrm{hCG}$ as a diagnostic test in hypertensive disorders of pregnancy were $65 \%$ and $86 \%$ respectively. Sensitivity values between $15 \%$ and $79 \%$ and specificity values between $15 \%$ and $90 \%$ can be found in published reports on serum $\beta$-hCG concentrations as a predictor of severe pre-eclampsia. ${ }^{22-25}$ Vaillant et al determined the $\beta$-hCG cutoff point to be 41,082 IU/L and Sahar et al determined that with cutoff point of $35,000 \mathrm{IU} / \mathrm{L}$, the sensitivity, specificity and total accuracy of $\beta$-hCG as a diagnostic test in preeclampsia was $75.00 \%, 77.14 \%$ and $76.12 \%$ respectively and the sensitivity, specificity and total accuracy of $\beta$-hCG for differentiation between mild and severe preeclampsia was $56.25 \%, 91.43 \%$ and $74.63 \%$ respectively with cutoff point of 50,000 IU/L. ${ }^{26,27}$ Yousefnejad et al reported $68 \%$ sensitivity and $63 \%$ specificity of $\beta$-hCG as a diagnostic test in preeclampsia with a cutoff point of 20,153 $\mathrm{mIU} / \mathrm{ml}^{20}$

\section{CONCLUSION}

A major challenge in obstetrics is early identification of hypertensive disorders of pregnancy. While the ability to predict HDP before they become symptomatic is of limited benefit as neither its development nor progression can be prevented in most patients, timely diagnosis is of utmost importance. As HDP cause significant maternal and fetal mortality and morbidity, early diagnosis may improve maternal and perinatal outcome by ensuring appropriate management.

Serum $\beta$-hCG level is higher in hypertensive disorders of pregnancy when compared to normotensive women. The levels are also higher in severe preeclampsia patients when compared with non- severe preeclampsia; and in primigravid hypertensive women in comparison to multigravida hypertensive women. It is also observed that the serum $\beta$-hCG levels are more in cases of early onset preeclampsia. Therefore, estimation of the serum $\beta$-hCG levels may help in the early diagnosis of HDP and it may as well serve as an indicator of the severity of the disease. 
There is an absolute need for a greater number of studies to conclude as to whether abnormally elevated serum hCG levels and arterial blood pressure are associated with increased risk for adverse outcomes in pregnancy and future cardiovascular disease in the mother.

The utility of serum $\beta$-hCG as a diagnostic test is limited because of low sensitivity and difficulty in deciding the cut-off value. Hence further studies are required on a larger series of patients to confirm the significance of serum $\beta$-hCG as a screening test for HDP. Serum $\beta$-hCG can be combined with other serum markers like pregnancy-associated plasma protein (PAPPA), alpha fetoprotein (AFP) and ultrasound parameters like Doppler study of uterine vessels, which will further help in improving its role as a screening tool.

Funding: No funding sources Conflict of interest: None declared

Ethical approval: The study was approved by the Institutional Ethics Committee

\section{REFERENCES}

1. Sajith M, Nimbargi V, Modi A, Sumariya R, Pawar A. Incidence of pregnancy induced hypertension and prescription pattern of antihypertensive drugs in pregnancy. Int J Pharma Sci Res. 2014;23:4.

2. Misra R, Donald's I. Practical Obstetrics problems; $6^{\text {th }}$ edition; Oracle BI publisher. 2006;14:300-1.

3. Chua S, Arulkumaran S, Eclampsia-no room for complacency. Singapore Med J. 1995;36:470-1.

4. Roiz-Hernandez J, de Cabello-Martinez J, Fernandez Mejia M. Human chorionic gonadotropin levels between 16 and 21 weeks of pregnancy and prediction of preeclampsia. Int $\mathbf{J}$ Gynecol Obstet. 2006;92:101-5.

5. Redman CWG. Platelets and the beginning of preeclampsia. N Eng J Med. 1990;323:478-80.

6. Long PA, Oat JN. Preeclampsia in twin pregnancy: severity and pathogenesis. Aust NZ J Obstet Gynecol. 1987;27:1-5.

7. Curry SL, Hammond CB, Tyrey L, Creasman WT, Parker RT. Hydatidiform mole: diagnosis, management and long term follow up of 374 patients. Obstet Gynecol. 1975;45:1-8.

8. Kumari A. Retrospective analysis of maternal mortality in a referral medical college, Jharkhand. Indian Med J. 2016;110:74(A)-77(A).

9. Berg CJ, Harper MA, Arkinson SM, Bell EA, Brown HL, Hage ML, et al. Preventability of pregnancyrelated deaths. Obstet Gynecol. 2005;106:1228-34.

10. Begum Z, Ara I, Tanira S, Keya K. The association between serum beta-human chorionic gonadotropin and preeclampsia. J Dhaka Med Coll. 2014;23(1):8993.

11. Basirat Z, Barat S, Hajiahmadi M. Serum beta human chorionic gonadotropin levels and preeclampsia. Saudi Med J. 2006;27(7):1001-4.
12. Choudhury KM, Das M, Ghosh S, Bhattacharya D, Ghosh TK. Value of serum $\beta$-hCG in pathogenesis of pre-eclampsia. J Clin Gynecol Obstet. 2012;1(45):71-5.

13. Mujawar SA, Patil VW, Daver RG. Serum human chorionic gonadotropin as a biochemical marker of adverse pregnancy outcome in severe preeclampsia. Am J Biochem. 2018;8(1):13-7.

14. Kaur G, Jain V, Mehta S, Himani S. Prediction of PIH by maternal serum beta HCG levels in the second trimester (13-20 weeks) of pregnancy. The J Obstet Gynecol India. 2012;62(1):32-4.

15. Al-bayati MM, Hammod NJ. Elevated serum $\beta$-hCG levels in severe pre-eclampsia. Iraqi J Med Sci. 2009;7(1):96-101.

16. Jaiswar SP, Nisha, Mamta R. Maternal human chorionic gonadotrophin as a predictor for pregnancy induced hypertension. J Obstet Gynecol Ind. 2003;53(6):543-5.

17. Mooney RA, Arvan DA, Saller DN, French CA, Peterson CJ. Decreased maternal serum hCG levels with increasing gravidity and parity. Obstet Gynecol. 1995;86:900-5.

18. Shenhav S, Gemer O, Sassoon E, Volodarsky M, Peled R, Segal S. Mid-trimester triple test levels in early and late onset sever pre-eclampsia. Prenat Diagnos. 2002;22:579-82.

19. Moodley D, Moodley J, Buck R, Haneet R, Payne A. Free alpha subunit of human chorionic gonadotropin in pre-eclampsia. Int J Gynecol Obstet. 1995;49:2837.

20. Yousefnejad K, Moslemizadeh N. Serum $\beta$-hCG levels in diagnosis and management of preeclampsia. J Med Sci. 2008;8(8):722-7.

21. Huppertz B. Placental origins of pre-eclampsia; challenging the current hypothesis. Hypert. 2008;51:970-5.

22. Dutta DC. Text book of obstetrics. $8^{\text {th }}$ edition, Chapter 17; Hypertensive disorders in pregnancy. Central Publishers; 2016:221-242.

23. Levine RJ, Hauth JC, Curet LB, Sibai BM, Catalano PM, Morris CD,et al. Trial of calcium to prevent preeclampsia. N Engl J Med. 1997;337:69-76.

24. Hofmeyr GJ, Lawrie TA, Atallah AN, Dubey L. Calcium supplementation during pregnancy for preventing hypertensive disorders and related problems. Cochrane Database Syst Rev. 2010;8:CD001059.

25. Barros JS, Baptista MG, Bairos VA. Human chorionic gonadotrophin in human placentas from normal and preeclamptic pregnancies. Arch Gynecol Obstet. 2002;266(2):67-71.

26. Vaillant P, David E, Constant I, Athmani B, Devulder G, Fievet P, et al. Validity in nulliparas of increased beta-human chorionic gonadotropin at mid-term for predicting pregnancy-induced hypertension complicated with proteinuria and intrauterine growth retardation. Nephron. 1996;72:557-63 
27. Sahar MY, El-Baradie, Mahmoud M, Makhlouf HH. Elevated serum levels of interleukin-15, interleukin16 , and human chorionic gonadotropin in women with pre-eclampsia. J Obstet Gynaecol Can. 2009;31(2):142-8.
Cite this article as: Kumari A, Vahini M. Association between maternal serum beta human chorionic gonadotropin levels and hypertensive disorders of pregnancy. Int J Reprod Contracept Obstet Gynecol 2020;9:3157-64. 